\title{
The Efficacy and Safety of Abrocitinib as a Treatment Option for Atopic Dermatitis: A Short Report of the Clinical Data
}

This article was published in the following Dove Press journal: Drug Design, Development and Therapy

\author{
Maddalena Napolitano (D) \\ Gabriella Fabbrocini ${ }^{2}$ \\ Angelo Ruggiero ${ }^{2}$ \\ Vincenzo Marino ${ }^{2}$ \\ Mariateresa Nocerino ${ }^{2}$ \\ Cataldo Patruno ${ }^{3}$ \\ 'Department of Medicine and Health \\ Sciences Vincenzo Tiberio, University of \\ Molise, Campobasso, Italy; ${ }^{2}$ Section of \\ Dermatology, Department of Clinical \\ Medicine and Surgery, University of \\ Naples Federico II, Naples, Italy; \\ ${ }^{3}$ Department of Health Sciences, \\ University Magna Graecia of Catanzaro, \\ Catanzaro, Italy
}

\begin{abstract}
Atopic dermatitis (AD) is a chronic, pruritic, inflammatory skin disease that predominantly affects children. However, it can persist in adulthood and/or start at older ages. Both dysfunction of the epidermal barrier and immune dysregulation are known to play a role in the pathogenesis of $\mathrm{AD}$. In the last years, numerous studies showed that Janus kinase (JAK) enzymes have a key role in AD pathogenesis. Therefore, oral and topical JAK inhibitors are new emerging treatments for AD. We report the data relating to abrocitinib, an oral JAK1 inhibitor. For this purpose, we examined articles already published concerning, in particular, concluded clinical trials. Furthermore, we also report the design of current ongoing clinical trials. The search was carried out considering the main search engines relating to medical literature and clinical trials. From all the data we collected, abrocitinib proved to be an effective drug in significantly reducing the severity of moderate-to-severe $\mathrm{AD}$ when compared to placebo. Furthermore, the efficacy was similar to other well-established treatment for $\mathrm{AD}$, such as dupilumab. Adverse events were generally mild; indeed, the drug was definitively suspended only in few patients.
\end{abstract}

Keywords: atopic dermatitis, abrocitinib, JAK inhibitors, JAK-STAT

\section{Introduction}

Atopic dermatitis (AD) is a chronic skin condition that has recently been the subject of volumes of basic science, clinical, and epidemiologic research, being considered a global health issue due to the increased prevalence in last decades. ${ }^{1,2}$ Currently, $\mathrm{AD}$ impacts approximately $15 \%$ to $20 \%$ of children and $10 \%$ of adults in industrialized countries, although there is a considerable countrywide variation of AD prevalence and severity. ${ }^{3}$

$\mathrm{AD}$ has a complex and multifactorial pathophysiology, consisting of multiple interactions between skin barrier defects and immunological disturbances. ${ }^{4}$ The most important pathway involved in $\mathrm{AD}$ pathogenesis is based on the T-helper (Th)2 lymphocyte axis. However, Th17, Th22, and Th1 cytokines have been shown to play important different roles in $\mathrm{AD} .^{4-8}$

The dysfunction of the skin barrier has been shown to be a fundamental alteration in the development of AD. Indeed, many alterations were related to skin barrier defects, such as immune dysregulation, filaggrin mutations, and skin dysbiosis. ${ }^{6}$ These factors interact with each other and may represent a trigger for immune activation, leading to an increase of interleukin (IL)-25, IL-33 as well as an increased activation of Th-2
Correspondence: Maddalena Napolitano Department of Medicine and Health Sciences Vincenzo Tiberio, University of Molise, Campobasso, Italy

Tel +390817462439

Email maddy.napolitano@gmail.com 
pathways. ${ }^{9}$ These results in a downregulation of envelope proteins (filaggrin, loricrin, and claudins) and of defensive epithelial barrier proteins. ${ }^{4,9}$ The activation of Th2 pathways is also related to increased levels of IL-4, IL-13, and IL-31, key cytokines associated with type- 2 inflammation. Indeed, their levels correlate with $\mathrm{AD}$ disease activity. ${ }^{10}$ Recently, some studies emphasized the role of innate lymphoid cells in expanding Th2 immunity through the release of IL-5 and IL13, which in turn increase and support Th2 response. ${ }^{11} \mathrm{Th} 2$ polarization facilitates Staphylococcus aureus binding and colonization, and IL-4 and IL-13 inhibit skin production of antimicrobial peptides, predisposing $\mathrm{AD}$ skin to bacterial infections. $^{12}$ Furthermore, S. Aureus may induce modifications in skin barrier, inducing inflammatory processes via super-antigens and toxic shock syndrome toxin-1, which trigger cytokine release. ${ }^{4}$

The chronic stage of AD is characterized by intensified Th2 and Th22 axes, and activation of both Th1 and Th17 cells. ${ }^{10}$ Th1 pathway activation induces an upregulation of interferon gamma and IL-12, leading to the promotion of chronic inflammation and keratinocytes apoptosis. ${ }^{4}$ Th17 cytokines IL-17 and IL-22 contribute to immune dysregulation in $\mathrm{AD}$, barrier abnormalities by down-regulating filaggrin, and down regulation of expression of keratinocyte genes associated with cellular adhesion. ${ }^{12,13}$

The Janus kinase (JAK)-signal transducer and activator of transcription (STAT) signalling has been shown to play a central role in AD pathogenesis. ${ }^{14}$ The JAK kinase family is composed of JAK1, JAK2, JAK3 and tyrosine kinase 2 (TYK2). ${ }^{15}$ While JAK1, JAK2, and TYK2 are expressed in all cells, JAK3 expression occurs primarily in hematopoietic cells. ${ }^{15}$ They operate intracellularly as signal transducers after that different cytokine bind their receptor chains associated with a JAK enzyme (Figure 1). ${ }^{16}$ The activation and dimerization of receptor activates JAK phosphorylation, leading to the binding with STAT, and subsequently STAT phosphorylation. ${ }^{17}$ The resulting STAT dimer translocates to the nucleus and modulates the upregulation of the proinflammatory cytokines and growth factors genes transcription. ${ }^{17}$ Each JAK dimer can be triggered by various cytokines and,

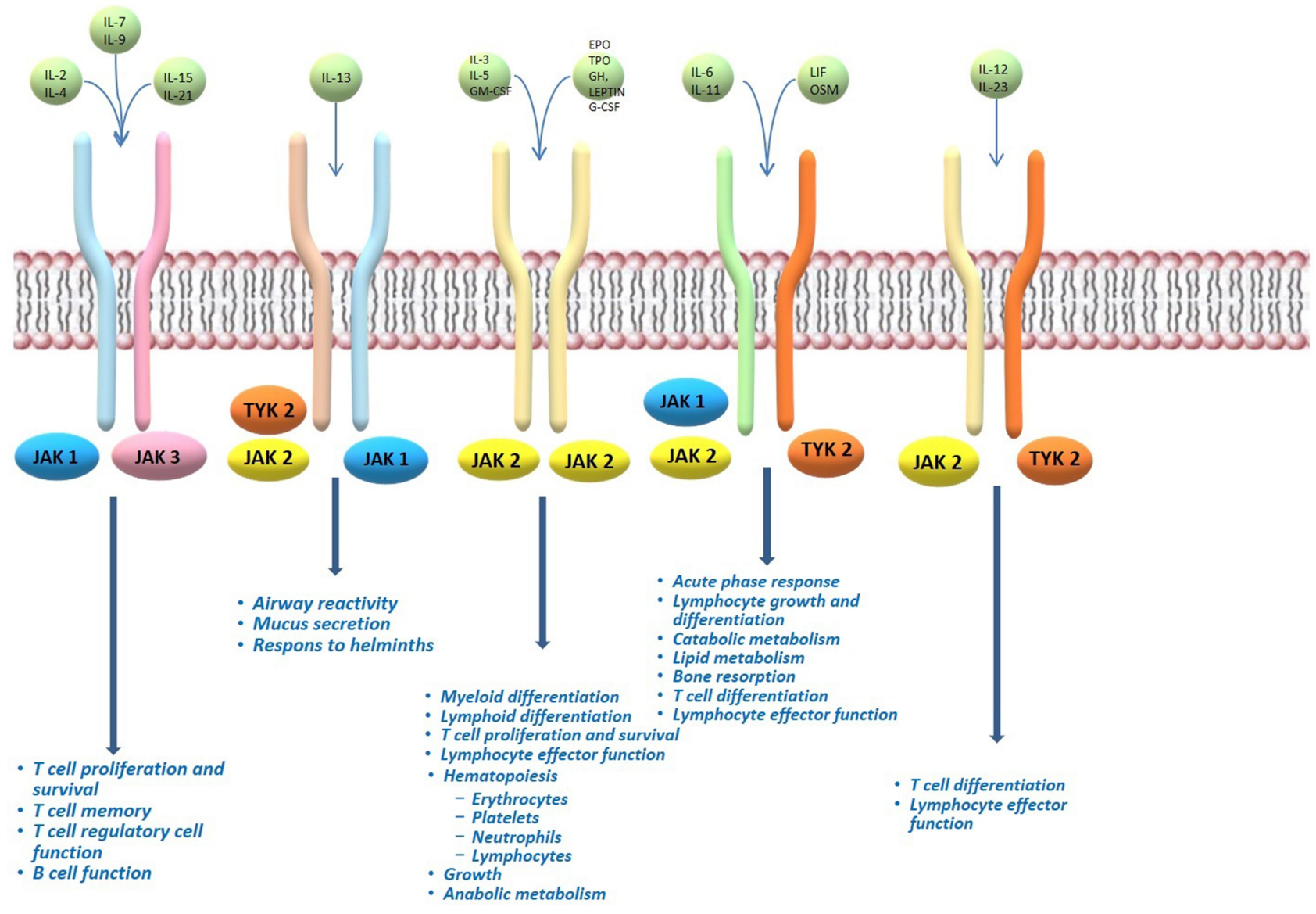

Figure I Overview of JAK signalling in the different features of immune-cell development and function. 
sequentially, activate different STAT proteins. ${ }^{16}$ JAK1 can dimerize with JAK2, JAK3, and TYK2; JAK2 with itself or TYK2; JAK3 only with JAK1; and TYK2 with JAK1 and JAK2. ${ }^{16}$ Numerous studies showed that in AD pathogenesis there is an upregulation of epidermal chemokines, proinflammatory cytokines, and pro-angiogenic factors, as well as downregulation antimicrobial peptides and factors responsible for skin barrier function, all induced by the JAKSTAT pathway activation. ${ }^{18}$ In particular, Th2 cytokines are mostly responsible for JAK1 and JAK3 activation, and the next subsequent phosphorylation of STAT6. ${ }^{4}$

Oral and topical JAK inhibitors are new emerging treatments for AD. ${ }^{19}$ The inhibition of JAK prevents their phosphorylation, stopping the transduction of intracellular signaling. ${ }^{20}$ First-generation JAK inhibitors block multiple JAKs. ${ }^{21}$ Among these, baricitinib, an oral JAK1 and JAK2 inhibitor, was recently approved for the treatment of moderateto-severe $\mathrm{AD}$ in adult patients who are candidates for systemic therapy. ${ }^{22}$ Second-generation JAK inhibitors target only one JAK isoform. ${ }^{20}$ Particularly, the selective JAK1-inhibition is important to modulate different cytokines involved in the $\mathrm{AD}$, avoiding undesirable effects related to the inhibition of JAK2 (neutropenia and anaemia). ${ }^{23}$ Abrocitinib (PF-04965842) is a recently introduced oral JAK1 selective inhibitor that influences different important cytokines signalling pathways involved in the AD, like IL-4, IL-13, and IL-31 (Figure 2). ${ }^{23}$

We herein present a review, which summarizes the data on efficacy and safety of abrocitinib in the treatment of moderate to severe AD.

\section{Methods}

A search in the PubMed, Embase, Cochrane Skin databases, and clinicaltrials.gov (until October 31, 2020) was performed using the search: "atopic dermatitis" or "atopic eczema" associated with "JAK1 inhibitors", "abrocitinib", or "PF-04965842". Only the material in English language was selected. The resulting records were further redefined through full-text review. Each author independently reviewed all the articles and data. Subsequently, they compared their opinions on the content and shared the information to be reported in the review. Only the articles and data already published were included in the review. Moreover, the reference lists of those papers were examined to retrieve other studies that were considered relevant for our aim. Implementing these search criteria, we also evaluated the clinical trials ongoing, but with no results posted.

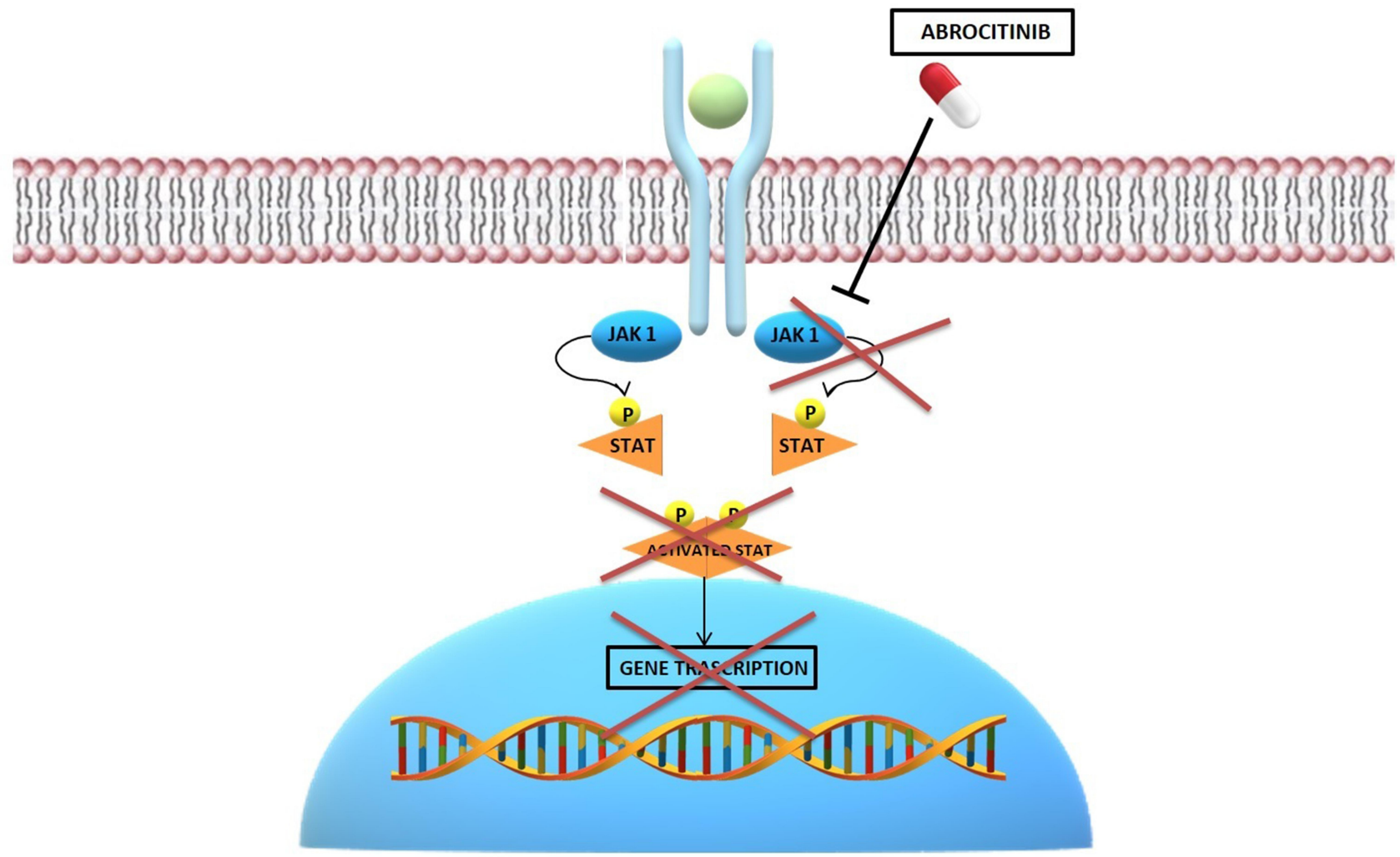

Figure 2 Schematic representation of the abrocitinib mechanism of action. 


\section{Results}

A total of 15 records were identified for evaluation in this review. Among these, we selected 5 clinical trials of Phase I, II and III, reviewing data about effectiveness and safety of abrocitinib. We also describe 5 trials that are currently ongoing and whose results, therefore, are not yet available. The clinical trials considered in this review are summarized in Table 1. Furthermore, we selected 5 reviews, which could be useful for the consultation and interpretation of the data. Letters and comments, reviews of abrocitinib in other dermatological diseases, and papers in which, according to the opinion shared by all the authors, there was no relevant information were excluded.

\section{Phase I}

The Phase I study (NCT01835197) evaluated abrocitinib safety, tolerability, pharmacokinetics and pharmacodynamics in 79 healthy adults. ${ }^{24}$ This was a single-center, double-blind (subject and investigator), and sponsor open study. ${ }^{24}$ The patients received a single ascending dose phase (SAD) of placebo or 3, 10, 30, 100, 200, 400, or $800 \mathrm{mg}$ of abrocitinib and placebo or $30 \mathrm{mg}$ once daily, $100 \mathrm{mg}$ once daily, $200 \mathrm{mg}$ once daily, $400 \mathrm{mg}$ once daily, $100 \mathrm{mg}$ twice daily, or $200 \mathrm{mg}$ twice daily of abrocitinib for 10 consecutive days [multiple ascending dose phase] (MAD). ${ }^{24}$ After abrocitinib intake, the peak plasma concentration has been observed within 1 hour (in both SAD and MAD phases) with a mean half-life of $2.8-5.4$ hours. ${ }^{24}$ Urinary recuperation was less than $4.4 \%$ and kidney excretion about 0.6 $\mathrm{L} \mathrm{h}^{-1.24}$ No serious adverse events (AEs) or death have been reported. Common AEs were headache (16.14\%), nausea (13.9\%), and diarrhoea $(13.9 \%) .{ }^{24}$ Only 4 treated patients discontinued due to AEs. For 3 of them, the drug discontinuation was considered treatment-related by the investigators ( 2 patients referred vomiting and one patient developed a respiratory syncytial virus infection), while for one patient the appearance of a second-degree atrioventricular block was not considered treatment-related. ${ }^{24}$ The most common abnormal laboratory tests were a decrease in mean platelet volume and a positive urine blood test in the SAD phase, and a reduction in reticulocyte counts and in mean platelet volume, and an increased lymphocyte counts in the MAD phase. $^{24}$

\section{Phase II}

Abrocitinib safety and efficacy were evaluated in a randomized, double-blinded, placebo controlled phase IIb trial (NCT02780167), including 267 adult patients aged 18-75 years with inadequate responses or contraindications to topical treatment. ${ }^{23}$ Patients were randomly treated with abrocitinib (200, 100, 30, or $10 \mathrm{mg}$ ) or placebo for 12 weeks. $^{23}$ Patients achieving an Investigator's Global Assessment (IGA) of clear (0) or almost clear (1) with an improvement from baseline of 2 grades or more at week 12 was the primary outcome, while secondary outcomes were the variation rate from baseline to week 12 in the Eczema Area and Severity Index (EASI), Body Surface Area (BSA), Scoring Atopic Dermatitis (SCORAD) and Pruritus Numerical Rating Scale (P-NRS). ${ }^{23}$

After 12 weeks, IGA0/1 was achieved by $43.8 \%, 29.6 \%$, $8.9 \%$ and $10.9 \%$ of patients treated with abrocitinib $200 \mathrm{mg}, 100 \mathrm{mg}, 30 \mathrm{mg}$, and placebo, respectively. ${ }^{23}$ Concerning the variation of EASI, in the group treated with abrocitinib $200 \mathrm{mg}$, there was a reduction of EASI of $82.6 \%$, while the reduction was of $59.0 \%$ and $40.7 \%$ in the groups treated with abrocitinib $100 \mathrm{mg}$ and $30 \mathrm{mg}$, respectively. ${ }^{23}$ A significant reduction of EASI was observed in both 200-mg and 100-mg groups compared with placebo, while these were not significant in the $30 \mathrm{mg}$ and $10 \mathrm{mg}$ groups. $^{23}$ At week 12, a significant reduction in P-NRS was observed in the $200 \mathrm{mg}$ and $100 \mathrm{mg}$ groups as well. P-NRS decreased and plateau by week 2 and week 4 in the $200 \mathrm{mg}$ and $100 \mathrm{mg}$ group, respectively. Finally, from baseline to week 12 a reduction of BSA and SCORAD in all treatment groups was observed. ${ }^{23}$ AEs were reported by 184 (68.9\%) patients. Of these $24.0 \%$ were considered related to treatments. $^{23}$ The most frequent reported AEs were upper respiratory tract infection, headache, nausea, diarrhoea, and $\mathrm{AD}$ worsening. ${ }^{23}$ Among patients treated with abrocitinib $200 \mathrm{mg}$ and abrocitinib $100 \mathrm{mg}$, a dose-dependent decrease in the platelet-count was found, which trended toward normalization. ${ }^{23}$ Two serious AEs were reported in the treatment groups: a case of pneumonia in the abrocitinib $200 \mathrm{mg}$ group and one case of eczema herpeticum in the abrocitinib $100 \mathrm{mg}$ group. ${ }^{23}$ Treatment discontinuation for AEs was reported in the $16.5 \%(n=44) .^{23}$

\section{Phase III JADE MONO-I}

In a multicentre, randomised Phase III trial (JADE MONO-1; NCT03349060), patients suffering from moderate-to-severe AD, were enrolled at 69 sites. $^{25}$ Patients were randomly assigned $(2: 2: 1)$ in one of the three study arms: abrocitinib $100 \mathrm{mg}$, abrocitinib $200 \mathrm{mg}$, and placebo QD for 12 weeks. $^{25}$ Enrolled patients have been suffering 


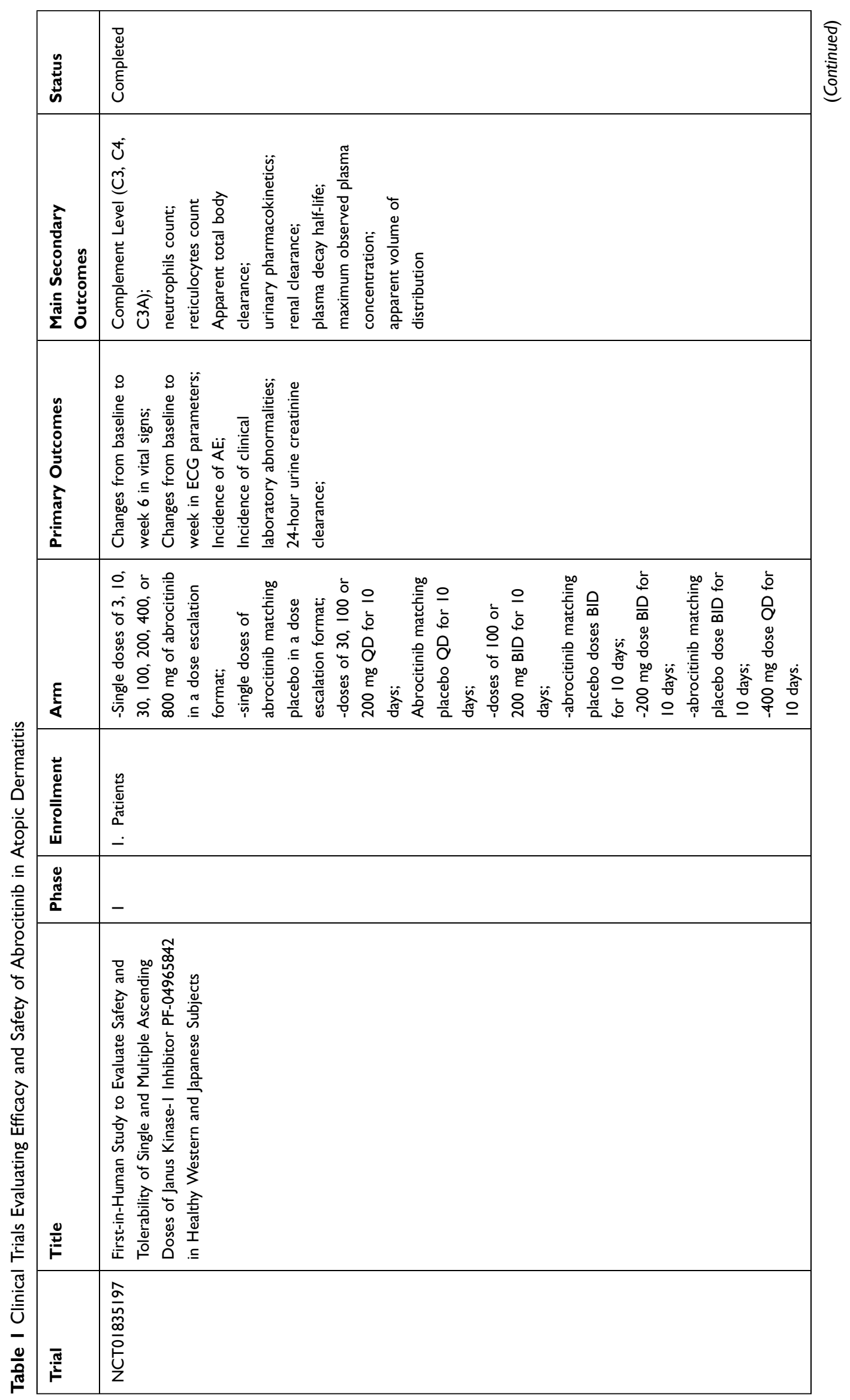




\begin{tabular}{|c|c|c|c|}
\hline 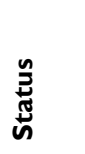 & 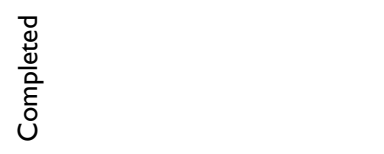 & 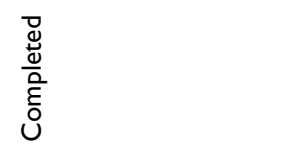 & 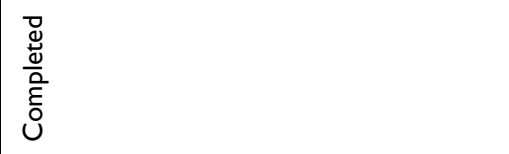 \\
\hline 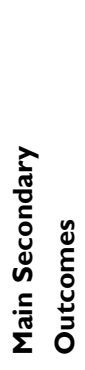 & 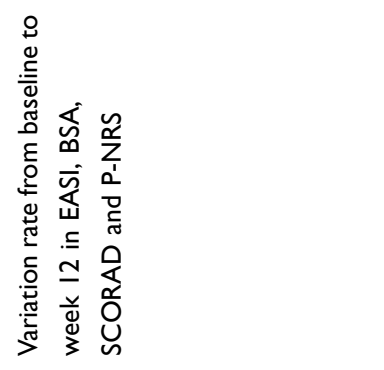 & 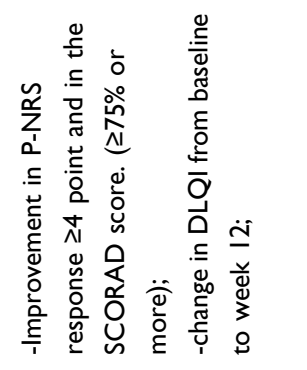 & 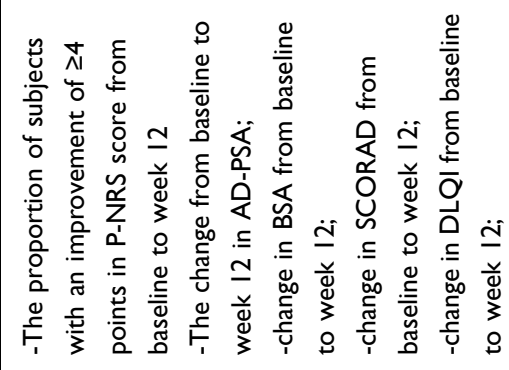 \\
\hline 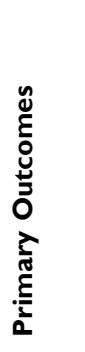 & 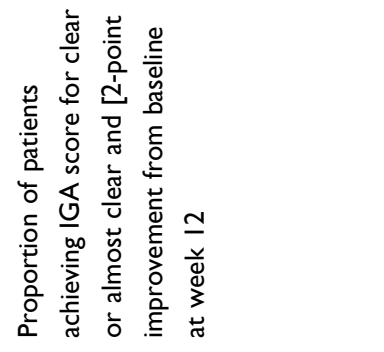 & 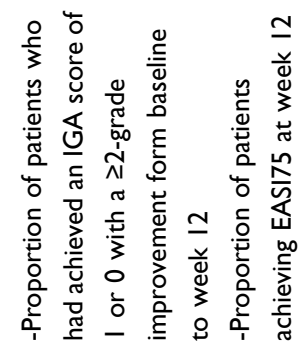 & 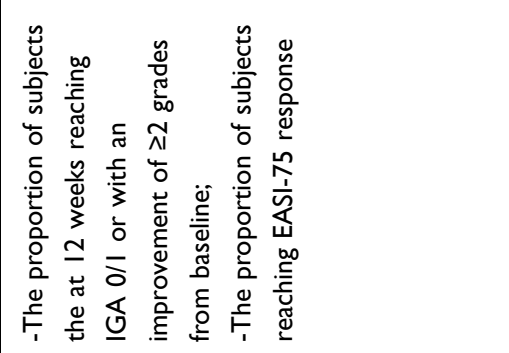 \\
\hline$\stackrel{\xi}{\frac{\xi}{\alpha}}$ & 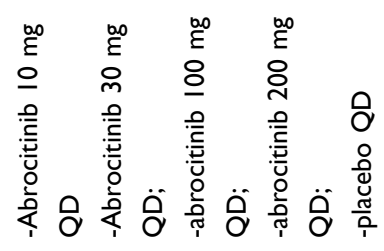 & 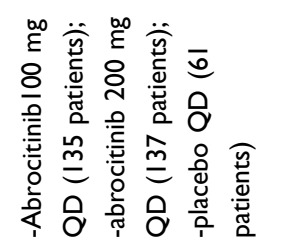 & 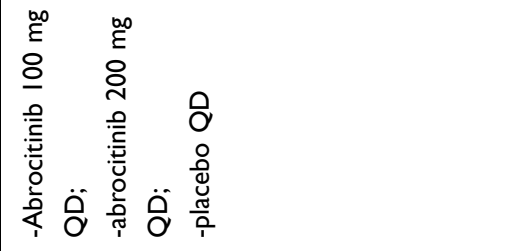 \\
\hline 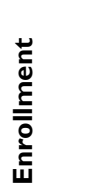 & 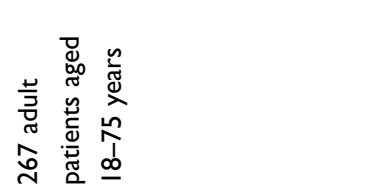 & 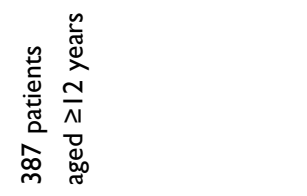 & 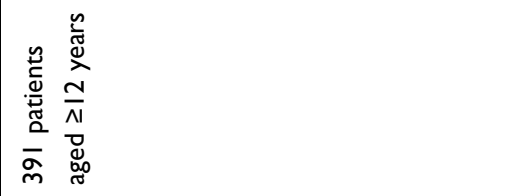 \\
\hline 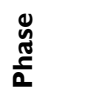 & $N$ & $m$ & $m$ \\
\hline$\stackrel{\varrho}{\stackrel{\Perp}{\mid}}$ & 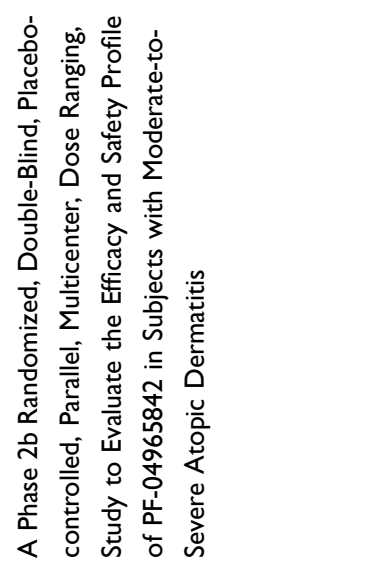 & 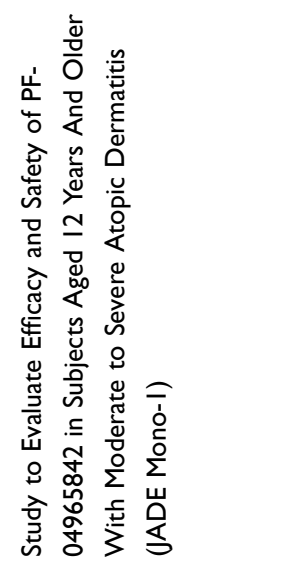 & 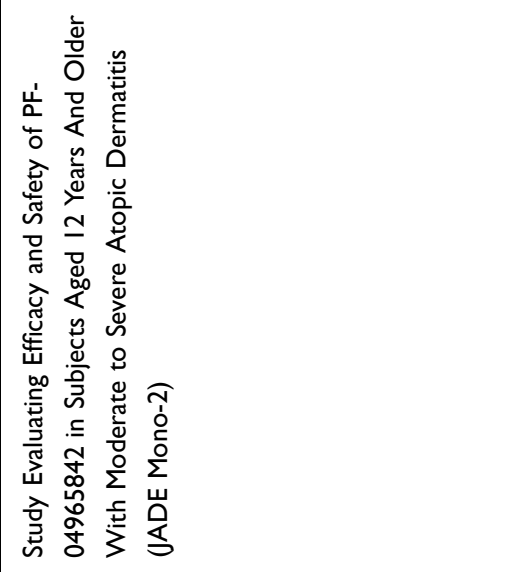 \\
\hline 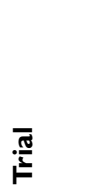 & 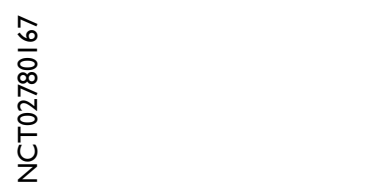 & 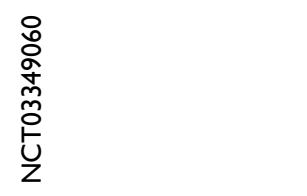 & 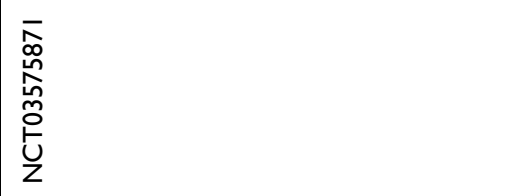 \\
\hline
\end{tabular}




\begin{tabular}{|c|c|}
\hline & 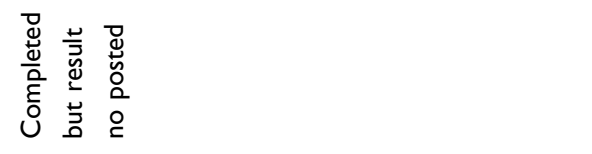 \\
\hline 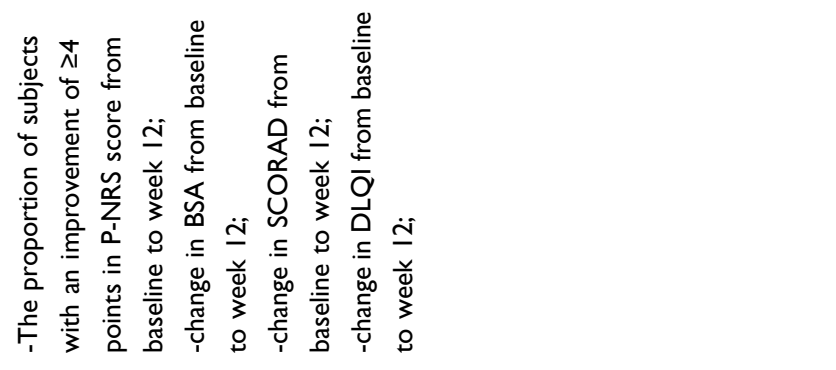 & 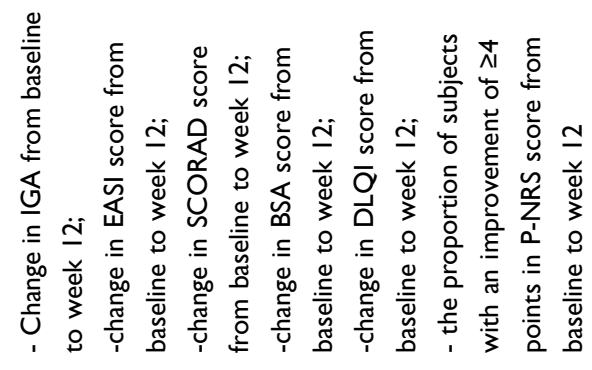 \\
\hline 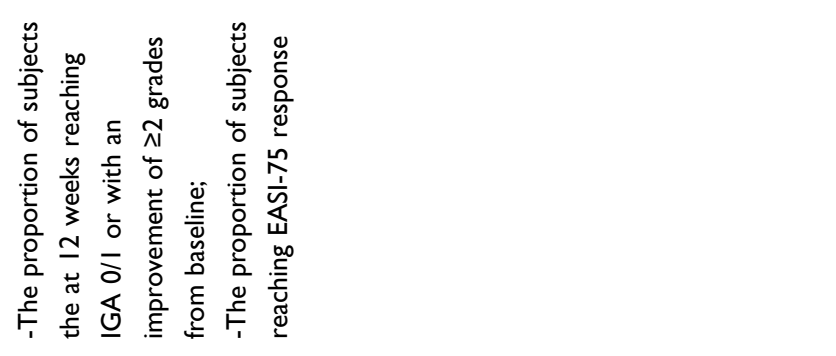 & 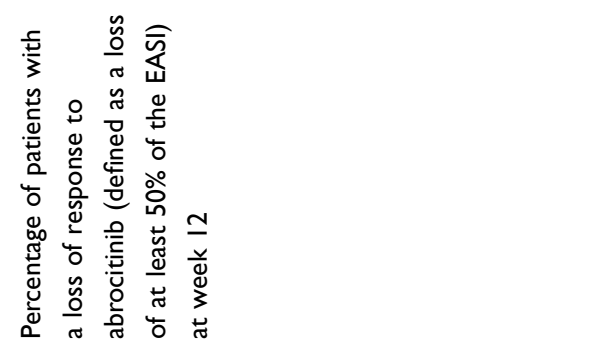 \\
\hline 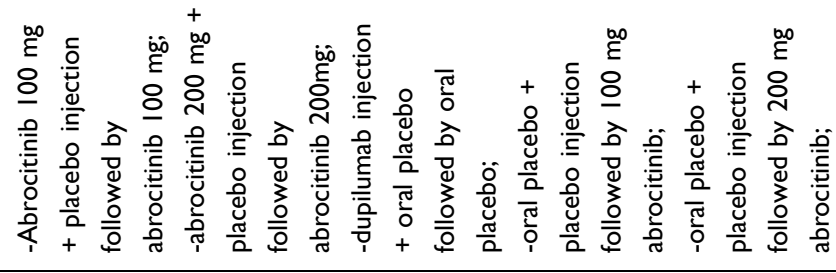 & 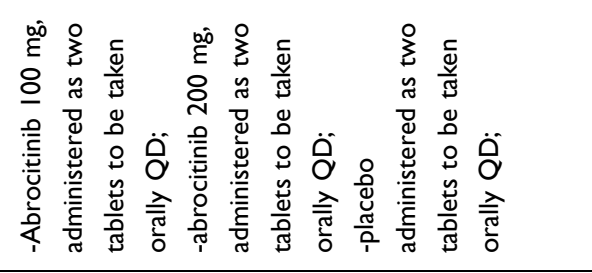 \\
\hline 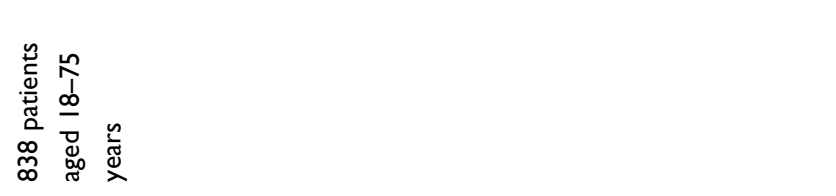 & 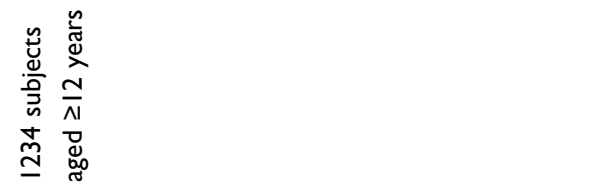 \\
\hline$m$ & $m$ \\
\hline 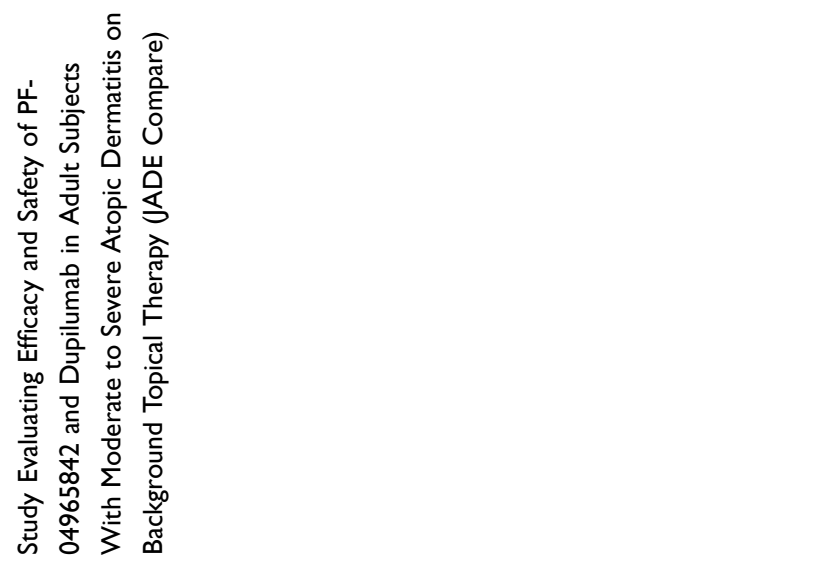 & 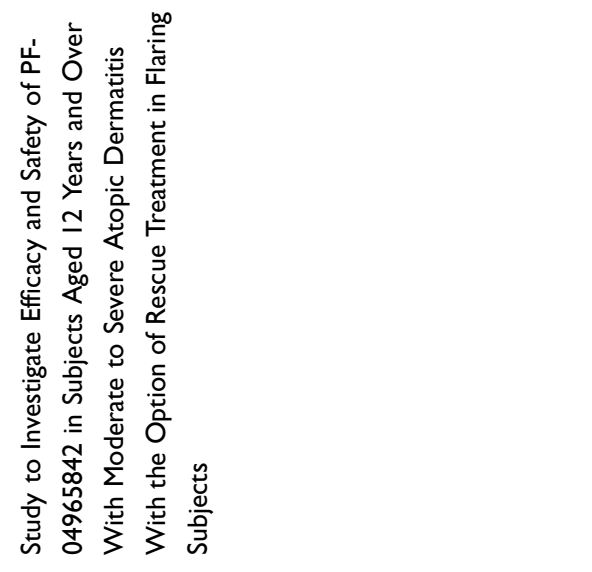 \\
\hline 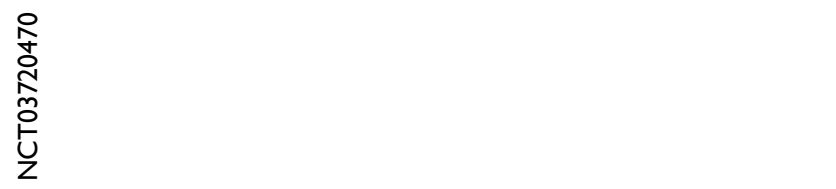 & 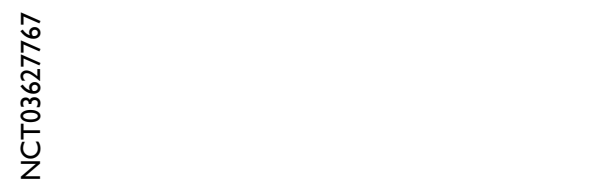 \\
\hline
\end{tabular}




\begin{tabular}{|c|c|c|c|}
\hline 总 & 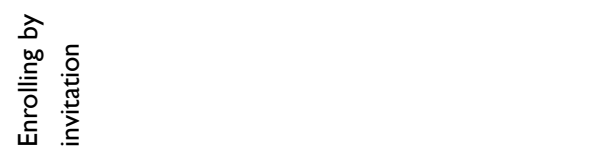 & 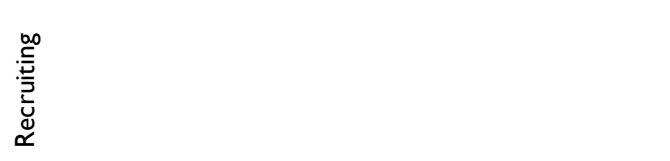 & $\begin{array}{l}\frac{0}{0} \\
\frac{0}{\bar{N}} \\
\frac{\pi}{8}\end{array}$ \\
\hline 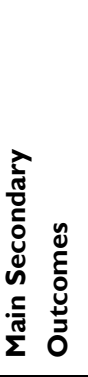 & 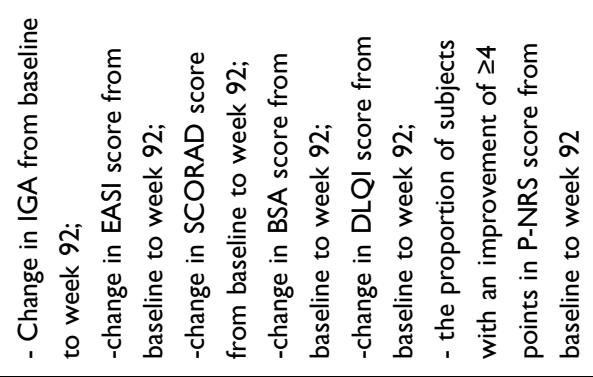 & 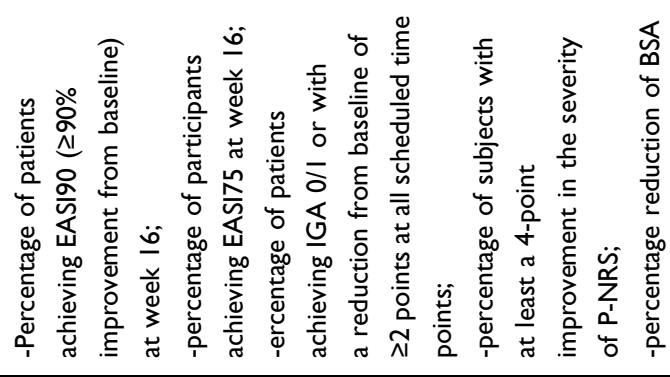 & 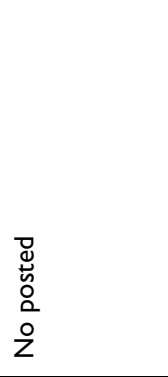 \\
\hline 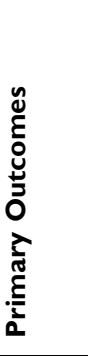 & 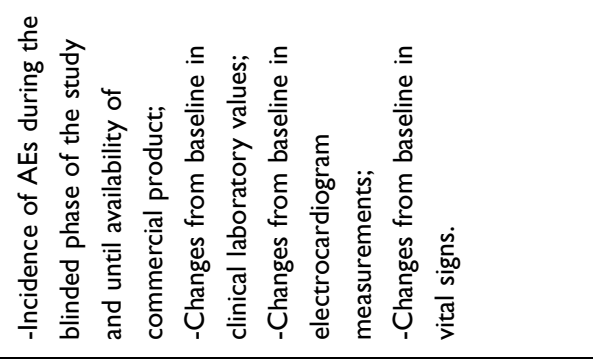 & 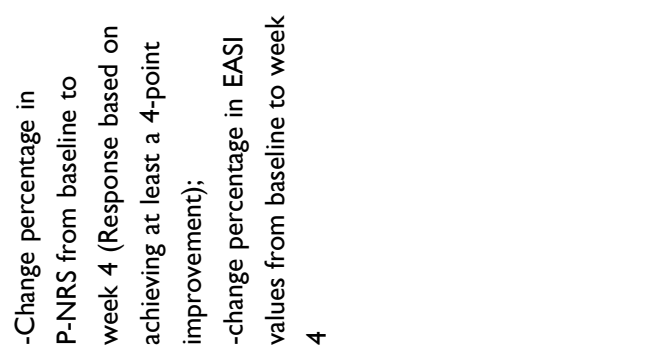 & 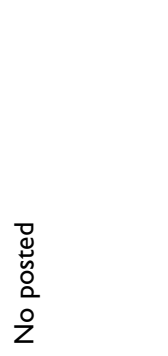 \\
\hline$\frac{\xi}{\frac{\xi}{\alpha}}$ & 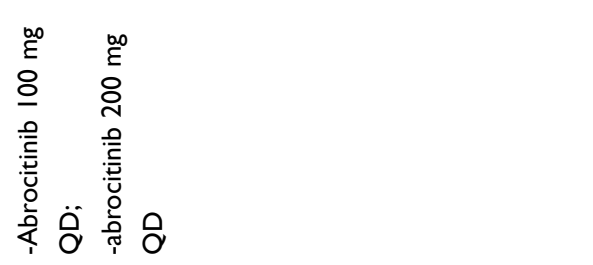 & 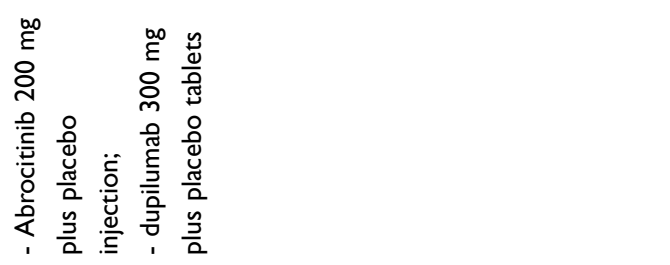 & 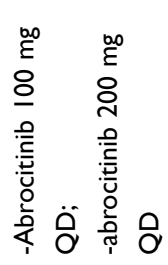 \\
\hline 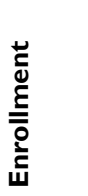 & 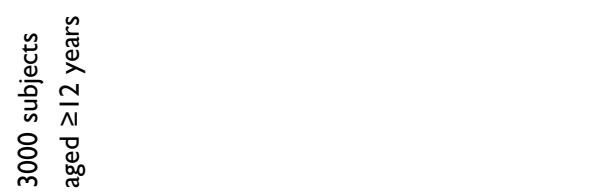 & 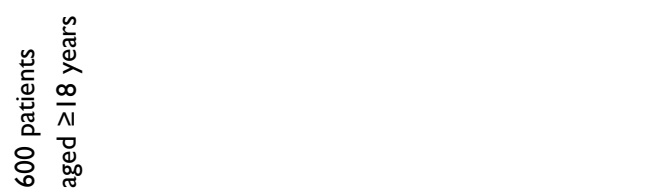 & 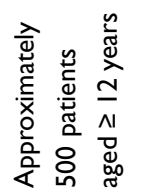 \\
\hline 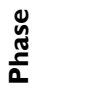 & $m$ & ले & $m$ \\
\hline 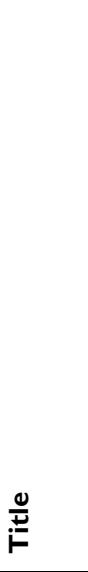 & 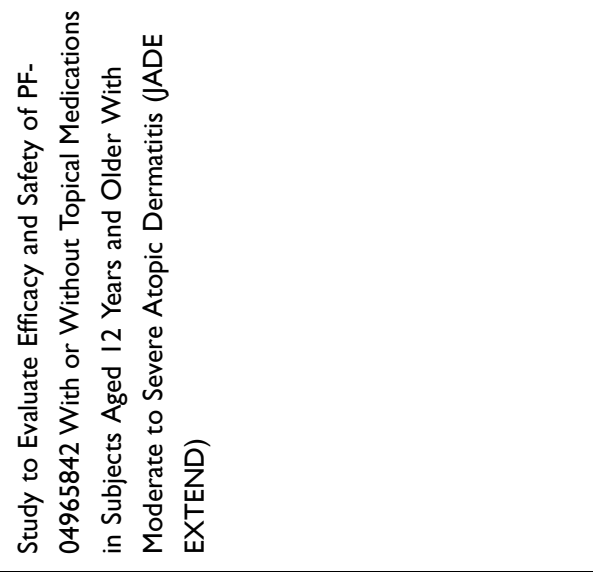 & 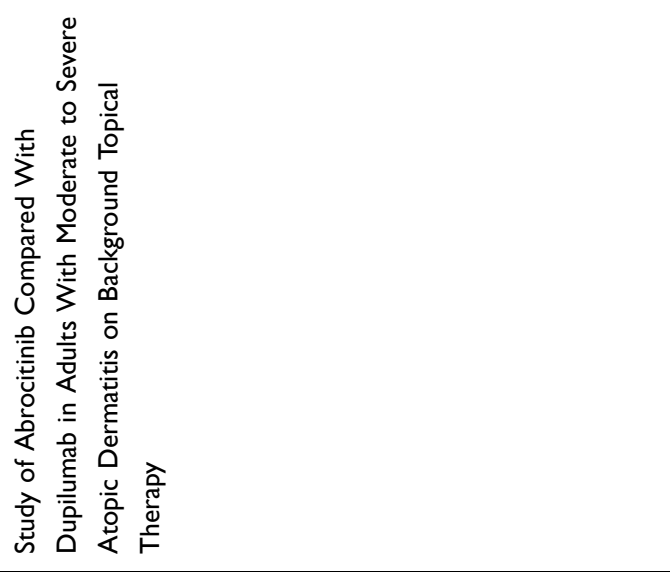 & 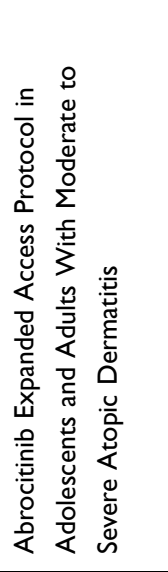 \\
\hline 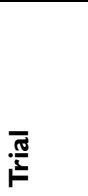 & 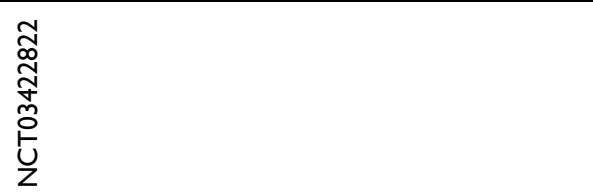 & 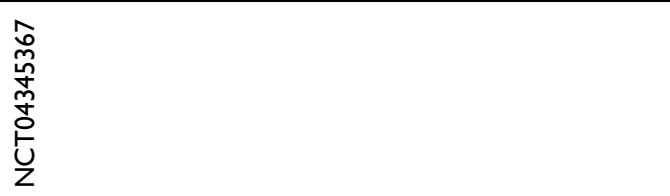 & 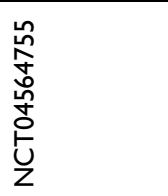 \\
\hline
\end{tabular}




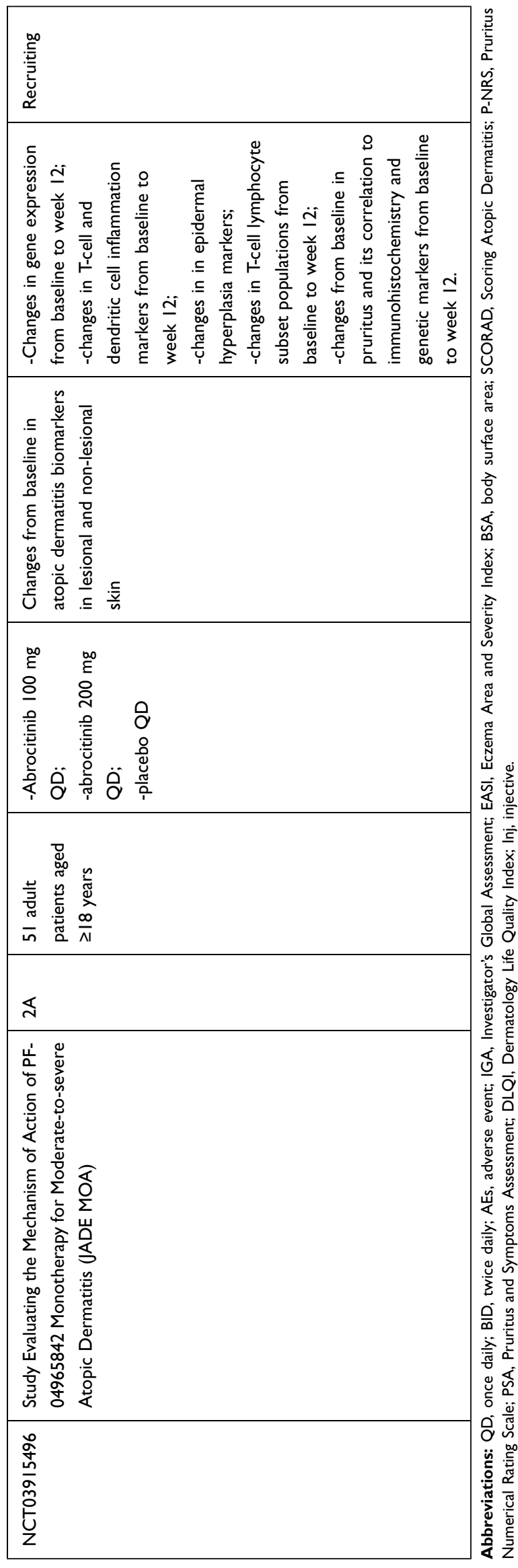

from $\mathrm{AD}$ for at least 1 year, showing IGA score $\geq 3$, EASI score $\geq 16$, BSA $\geq 10 \%$ and P-NRS $\geq 4 .{ }^{25}$ The coprimary endpoints were the proportion of patients who had achieved an IGA score of 1 or 0 with a $\geq 2$-grade improvement from baseline, and the proportion of patients achieving EASI75. ${ }^{25}$ The main secondary endpoints were the proportion of patients who from baseline to week 12 achieved a P-NRS response $\geq 4$ point improvement and an improvement of $\geq 75 \%$ or more in the SCORAD score.

Three hundred and eighty-seven patients were enrolled, but 333 patients concluded the study: 135 patients in the abrocitinib $100 \mathrm{mg}$ group, $137 \mathrm{in}$ the abrocitinib $200 \mathrm{mg}$ group, and 61 in the placebo group. After 12 weeks, IGA response was reached by $43.8 \%$ of patients of abrocitinib $200 \mathrm{mg}$ group, $23.7 \%$, of patients of $100 \mathrm{mg}$ group, and $7.9 \%$ placebo group. ${ }^{25}$ As regards the different variations in IGA responses between placebo and treatment groups, it was $15.8 \%(\mathrm{p}=0.0037)$ abrocitinib $100 \mathrm{mg}$ group and $36.0 \%(p<0.0001)$ in the abrocitinib $200 \mathrm{mg}$ group. ${ }^{25}$ Furthermore, EASI75 was achieved by $62.7 \%$ of patients receiving abrocitinib $200 \mathrm{mg}, 39.7 \%$ of subjects receiving abrocitinib $100 \mathrm{mg}$, and $11.8 \%$ of placebo group. ${ }^{25}$ A statistically significant improvement in the P-NRS score was observed in all treatment groups $(57.2 \%$ of patients receiving abrocitinib $200 \mathrm{mg}$ and $37.7 \%$ of those receiving abrocitinib $100 \mathrm{mg}$ ), vs $15.3 \%$ of placebo groups. ${ }^{25}$ An effective response in P-NRS has been already observed at week $2 .{ }^{25}$ P-NRS response was noted after a median of 14 days in patients treated with abrocitinib $200 \mathrm{mg}$, after a median of 84 days in patients treated with abrocitinib $100 \mathrm{mg}$ and a median of 92 days in patients treated with placebo. ${ }^{25}$ As regards SCORAD variations rates, these resulted considerably higher in abrocitinib treatment groups than placebo groups, reaching a SCORAD response of $\geq 75 \%$ in $30.8 \%$ and $12.4 \%$ of patients in the $200 \mathrm{mg}$ and $100 \mathrm{mg}$ arms, respectively, vs $4.1 \%$ of those in placebo group. ${ }^{25}$

In the JADE MONO-1 trial, AEs were described in $69 \%(\mathrm{n}=108)$ of the abrocitinib $100 \mathrm{mg}$ group, $78 \%$ $(\mathrm{n}=120)$ of the abrocitinib $200 \mathrm{mg}$ group, and $57 \%$ $(n=44)$ of the placebo group. The most frequent reported AEs were nasopharyngitis, headache, upper respiratory tract infection, nausea, and $\mathrm{AD}{ }^{25}$ Serious AEs were observed in 5/156 (3.2\%) of patients treated with abrocitinib $200 \mathrm{mg}$ (including: asthma, inflammatory bowel disease, dehydration, and peri-tonsillitis), in 5/154 (3.2\%) of abrocitinib $100 \mathrm{mg}$ group (appendicitis, seizures, dizziness and acute pancreatitis) and in 3/77 (3.9\%) of placebo 
group (worsening of $\mathrm{AD}$, appendicitis, and meniscal degeneration). ${ }^{25}$ Two serious AEs were considered treatment-related: one patient in the abrocitinib $200 \mathrm{mg}$ group developed chronic inflammatory bowel disease and another patient in the abrocitinib $100 \mathrm{mg}$ acute pancreatitis. ${ }^{25}$ Abrocitinib was permanently discontinued for both patients. ${ }^{25}$

The discontinuation rate in the $200 \mathrm{mg}$ and $100 \mathrm{mg}$ abrocitinib groups were respectively of $6 \%(n=9)$ and $6 \%$ $(\mathrm{n}=9)$, with $\mathrm{AD}$, gastrointestinal disorders, inflammatory bowel disease, and vomiting as most frequent causes of treatment discontinuation. ${ }^{25}$ However, the discontinuation rate resulted higher in the placebo group (9.1\%) than in the abrocitinib groups (5.8\%). A dose-related reduction of median platelet count was observed in both treatment groups (100 and $200 \mathrm{mg}$ ), with a nadir at week 4 . However, in all cases, there was a return to baseline values without requiring treatment discontinuation. ${ }^{25}$ No major cardiovascular events or venous thromboembolism or death have been reported. ${ }^{25}$

\section{JADE MONO-2}

In the JADE MONO-2 trial (NCT03575871), a multicentre, double-blind, randomised phase III trial, 391 patients suffering from moderate-to-severe AD were randomly assigned in the following treatment groups: i) monotherapy with QD abrocitinib $200 \mathrm{mg}$; ii) abrocitinib $100 \mathrm{mg}$; iii) placebo. ${ }^{26}$ The proportion of subjects at 12 weeks reaching IGA $0 / 1$ or with an improvement of $\geq 2$ grades from baseline and the proportion of subjects reaching EASI-75 response have been identified as primary end points. Secondary end points were the proportion of subjects with an improvement of $\geq 4$ points from baseline in P-NRS score, and the change from baseline to week 12 in the total score of an 11-item survey created to evaluate daily symptoms of AD [Pruritus and Symptoms Assessment (PSA)]. ${ }^{26}$

Three hundred and thirty patients completed the trial. After 12 weeks, abrocitinib treatment groups (both $200 \mathrm{mg}$ and $100 \mathrm{mg}$ groups) achieved significantly higher responses if compared to placebo group in terms of IGA 0/1 (38.1\%, 28.4\% vs 9.1\%), EASI 75 (61.0\%, 44.5\%, vs $10.4 \%$ ), and P-NRS $\geq 4$-point improvement $(55.3 \%, 23.9 \%$ vs $11.5 \%) .{ }^{26}$ P-NRS response was reached after a median time of 29 days in patients treated with abrocitinib $200 \mathrm{mg}, 58$ days in patients treated with $100 \mathrm{mg}$ and 112 days in patients treated with placebo. ${ }^{26} \mathrm{~A}$ significant reduction in P-NRS scores in both abrocitinib groups was firstly reported at day $1 .^{26}$ The reduction from baseline at week 12 in PSA total score was superior for both treatment groups compared to placebo group: $-3.0,-2.4$ and -0.8 for the patients treated with abrocitinib $200 \mathrm{mg}$, $100 \mathrm{mg}$ group and placebo, respectively. ${ }^{26}$

In the JADE MONO-2 trial, 65.8\% $(\mathrm{n}=102)$ of the $200 \mathrm{mg}$ group, $62.7 \%(\mathrm{n}=99)$ of the $100 \mathrm{mg}$ group, and $53.8 \%(\mathrm{n}=42)$ of the placebo group reported treatmentemergent AEs. ${ }^{17}$ The following were the most reported AEs: nausea in the $200 \mathrm{mg}$ group (14.2\%), nasopharyngitis in the $100 \mathrm{mg}$ group (12.7\%), and $\mathrm{AD}$ in the placebo group (15.4\%). In the $100 \mathrm{mg}$ abrocitinib group one death was reported, which was not related to the treatment. A total of 7 serious AEs were reported in the treatment groups. Of these, 2 AEs reported in the 100mg group were considered related to treatment and were a case of herpangina and a case of pneumonia. ${ }^{26}$ Both cases required abrocitinib discontinuation. Discontinuation rates were $3.2 \%, 3.8 \%$, and $12.8 \%$ of $200 \mathrm{mg}, 100 \mathrm{mg}$, and placebo group, respectively. Headache was the most frequent reported $\mathrm{AE}$ in both treatment groups (100 mg, $200 \mathrm{mg}$, and placebo). A reduction in platelet counts was described in the JADE MONO-2 as well, which returned to baseline levels despite the continuation of treatment.

\section{JADE COMPARE}

The JADE COMPARE study (NCT03720470) is a comparative study in which two dosages of abrocitinib, $100 \mathrm{mg}$ and $200 \mathrm{mg}$ taken orally QD were compared to placebo at 12 weeks and to dupilumab at 2 weeks in relation to decrease of itch. ${ }^{27}$ Co-primary endpoints are the proportion of patients achieved IGA $0 / 1$ or with a reduction from baseline of $\geq 2$ points at week 12 , and the proportion of patients achieving EASI-75. The study comprised 838 patients randomized into 5 arms of treatment: 1) patients randomized to take one of the two abrocitinib dosage plus a placebo injectable every 2 weeks until week 16 , and then kept on receiving only the abrocitinib for 4 weeks; ${ }^{27}$ 2) patients randomized in the arm dupilumab every 2 weeks and oral placebo QD until week 16 and after only oral placebo for 4 weeks; ${ }^{27} 3$ ) patients randomized to the placebo arm (in both injectable and oral form) every 2 weeks until week 16, and after in the arm abrocitinib $100 \mathrm{mg}$ or $200 \mathrm{mg}$ QD for 4 weeks. ${ }^{27}$ At week 12 IGA 0/1 EASI75 response resulted significantly higher in abrocitinib treated groups than placebo group. $^{27}$ These results were still maintained after 16 weeks. Similarly, patients treated with dupilumab reached 
similar outcomes when compared to placebo at both weeks 12 and $16 .^{7}$ Moreover, the percentage of patients who had a clinically significant reduction in P-NRS by week 2 was higher in abrocitinib $200 \mathrm{mg}$ group than dupilumab, and not statistically significantly higher, for the abrocitinib $100 \mathrm{mg}$ group than dupilumab. ${ }^{27}$ From the data currently available, the JADE COMPARE study showed a safety profile of abrocitinib consistent with prior trials. ${ }^{27}$

\section{Ongoing Clinical Trials Phase IIA}

In the JADE MOA study (NCT03915496), a multicentre, double-blind, randomised phase IIA study, the mechanism of action of abrocitinib is evaluated and correlated to efficacy outcomes, with changes from baseline in key skin and blood biomarkers in adult ( $\geq 18$-year-old) participants. ${ }^{32}$ The study provides for the enrolment of 51 patients and is currently in the recruiting phase. The participants will be randomized in a 1:1:1 ratio to receive abrocitinib $200 \mathrm{mg}$ once daily (QD), abrocitinib $100 \mathrm{mg}$ QD, or matching placebo QD for 12 weeks. The primary endpoint is the evaluation of expression in lesional and non-lesional skin of biomarkers for general inflammation (MMP12), hyperplasia (K16), Th2 immune response (CCL17, CCL18, CCL26), and Th22 immune response (S100A8, S100A9, S100A12), from baseline to week 12. ${ }^{32}$

\section{Phase III}

In the phase III study (JADE REGIMEN; NCT03627767) the efficacy and safety of abrocitinib has been evaluated in patients suffering from moderate to severe $\mathrm{AD}$, aged $\geq 12$ years, and with a body weight $\geq 40 \mathrm{~kg}^{28}$ The study included 1234 subjects. After an initial 12-week, openlabel treatment with abrocitinib $200 \mathrm{mg}$ QD, the patients have been randomized to receive abrocitinib $200 \mathrm{mg}$ QD, $100 \mathrm{mg}$ QD, or placebo QD. ${ }^{28}$ The primary endpoint is the percentage of patients that 12 weeks after the randomization showed a loss of response to abrocitinib (defined as a loss of at least $50 \%$ of the EASI) requiring rescue treatment during the blinded treatment period. The main secondary endpoints are the change of IGA, EASI, P-NRS, SCORAD, BSA, and DLQI, from baseline to all timepoints. The study enrolment has been completed, but no results are available. ${ }^{28}$

In the JADE EXTEND study (NCT03422822), multicenter, long-term extension trial, the efficacy and safety of abrocitinib has been evaluated in about 3000 atopic patients aged 12 years and older. ${ }^{29}$ Abrocitinib was administered in 2 dosages, $100 \mathrm{mg}$ and $200 \mathrm{mg}$ taken orally QD. ${ }^{29}$ After a 92-week initial treatment period, the patients received the same dosage treatment in open-label until drug availability in commerce. The co-primary endpoints were the evaluation of incidence of AEs during the blinded phase of the study and until availability of commercial product, the changes from baseline in clinical laboratory values, the electrocardiogram measurements, and the vital signs. The main secondary endpoints were percentage of reduction of IGA, EASI, P-NRS, and BSA from baseline to week 92. The study is currently in the enrolment phase and is expected to end in December 2023. No results are available. ${ }^{29}$

In a phase IIIb randomized clinical trial (NCT04345367), the effectiveness and safety of abrocitinib $200 \mathrm{mg}$ QD is compared to dupilumab $300 \mathrm{mg}$ administered by subcutaneous injection every other week. ${ }^{30}$ To date, the study is in the enrolment phase, and the randomization of about 600 subjects is planned. The primary endpoints are the change percentage in P-NRS and EASI values, from baseline to week 4 . The main secondary endpoints were: 1) the percentage of patients achieving EASI90 ( $\geq 90 \%$ improvement from baseline) at week $16 ; 2)$ the percentage of participants achieving EASI75 at week 16 ; 3) the percentage of patients achieving IGA 0/1 or with a reduction from baseline of $\geq 2$ points at all scheduled time points; 4) percentage of subjects with at least a 4-point improvement in the severity of P-NRS; 5) percentage reduction of BSA. ${ }^{30}$ The estimated study completion date is July 2021.

To date, a multicentre clinical trial (NCT04564755) provides access to abrocitinib treatment, to adolescent (from 12 years of age) and adult patients with moderate to severe $A D$ who have inadequate treatment options with available and approved medicated topical and systemic therapies. ${ }^{31}$ The participants will receive abrocitinib $100 \mathrm{mg}$ or $200 \mathrm{mg}$ orally QD. ${ }^{31}$ No further information is currently available. ${ }^{31}$

\section{Conclusion}

Selective JAK1 inhibitors seem to be effective and safe for AD treatment, with good oral bioavailability as well as a lack of immunogenicity, addressing some of the limitations of biologic drugs. Abrocitinib, among others, could change how to treat our moderate to severe $\mathrm{AD}$ patients. Indeed, the efficacy is significantly higher than placebo and seems to be comparable or higher than that of dupilumab, a monoclonal antibody largely used in 
patients with moderate-to-severe AD. Furthermore, abrocitinib improved pruritus firstly starting after 2 days of treatment. This rapid effect may increase adherence to treatment in patients before gaining clinical control of the disease. The safety and tolerability profile was acceptable; in fact, only few patients dropped-out during clinical trials. However, to evaluate its most appropriate role in AD treatment, it will be essential to have long-term real-life data and head-to-head studies for different JAK inhibitors and biologic drugs.

\section{Funding}

There is no funding to report.

\section{Disclosure}

MN has acted as speaker, consultant and advisory board member for Sanofi, Abbvie, Leo Pharma and Novartis.

GF has been principal investigator in clinical trials sponsored by and/or and has received personal fees from AbbVie, Abiogen, Almirall, Celgene, Eli-Lilly, Leo Pharma, Novartis, Sanofi, and UCB.

$\mathrm{CP}$ has acted as investigator, speaker, consultant, and advisory board member for AbbVie, Eli Lilly, Novartis, Pfizer and Sanofi.

The authors report no other potential conflicts of interest for this work.

\section{References}

1. Sidbury R, Kodama S. Atopic dermatitis guidelines: diagnosis, systemic therapy, and adjunctive care. Clin Dermatol. 2018;36:648-652. doi:10.1016/j.clindermatol.2018.05.008

2. Torres T, Ferreira EO, Gonçalo M, Mendes-Bastos P, Selores M, Filipe P. Update on atopic dermatitis. Acta Med Port. 2019;32:606-613. doi:10.20344/amp.11963

3. Napolitano M, Ruggiero A, Fontanella G, Fabbrocini G, Patruno C. New emergent therapies for atopic dermatitis: a review of safety profile with respect to female fertility, pregnancy, and breastfeeding. Dermatol Ther. 2020; 14475.

4. Szalus K, Trzeciak M, Nowicki RJ. JAK-STAT inhibitors in atopic dermatitis from pathogenesis to clinical trials results. Microorganisms. 2020;8:E1743. doi:10.3390/microorganisms 8111743

5. He H, Guttman-Yassky E. JAK inhibitors for atopic dermatitis: an update. Am J Clin Dermatol. 2019;20:181-192. doi:10.1007/s40257018-0413-2

6. Czarnowicki T, Krueger JG, Guttman-Yassky E. Novel concepts of prevention and treatment of atopic dermatitis through barrier and immune manipulations with implications for the atopic march. $J$ Allergy Clin Immunol. 2017;139:1723-1734. doi:10.1016/j. jaci.2017.04.004

7. Czarnowicki T, Gonzalez J, Shemer A, et al. Severe atopic dermatitis is characterized by selective expansion of circulating TH2/TC2 and TH22/TC22, but not TH17/TC17, cells within the skin-homing T-cell population. J Allergy Clin Immunol. 2015;136:104-115. doi:10.1016/j. jaci.2015.01.020
8. Werfel T, Allam J-P, Biedermann T, et al. Cellular and molecular immunologic mechanisms in patients with atopic dermatitis. J Allergy Clin Immunol. 2016;138:336-349. doi:10.1016/j.jaci.2016.06.010

9. Guttman-Yassky E, Waldman A, Ahluwalia J, Ong PY, Eichenfield LF. Atopic dermatitis: pathogenesis. Semin Cutan Med Surg. 2017;36:100-103. doi:10.12788/j.sder.2017.036

10. Chu CY. Treatments for childhood atopic dermatitis: an update on emerging therapies. Clin Rev Allergy Immunol. 2020. doi:10.1007/ s12016-020-08799-1

11. Salimi M, Barlow JL, Saunders SP, et al. A role for IL-25 and IL-33driven type-2 innate lymphoid cells in atopic dermatitis. $J$ Exp Med. 2013;210:2939-2950. doi:10.1084/jem.20130351

12. Brunner PM, Guttman-Yassky E, Leung DY. The immunology of atopic dermatitis and its reversibility with broad-spectrum and targeted therapies. $J$ Allergy Clin Immunol. 2017;139:S65-S76. doi:10.1016/j.jaci.2017.01.011

13. Gutowska-Owsiak D, Schaupp AL, Salimi M, et al. IL-17 downregulates filaggrin and affects keratinocyte expression of genes associated with cellular adhesion. Exp Dermatol. 2012;21:104-110. doi:10.1111/j.1600-0625.2011.01412.x

14. Cotter DG, Schairer D, Eichenfield L. Emerging therapies for atopic dermatitis: JAK inhibitors. $J$ Am Acad Dermatol. 2018;78:S53-S62. doi:10.1016/j.jaad.2017.12.019

15. Villarino AV, Kanno Y, O'Shea JJ. Mechanisms and consequences of Jak-STAT signaling in the immune system. Nat Immunol. 2017;18:374-384. doi:10.1038/ni.3691

16. Ferreira S, Guttman-Yassky E, Torres T. Selective JAK1 inhibitors for the treatment of atopic dermatitis: focus on upadacitinib and abrocitinib. Am J Clin Dermatol. 2020;21:783-798. doi:10.1007/ s40257-020-00548-6

17. Crowley EL, Nezamololama N, Papp K, Gooderham MJ. Abrocitinib for the treatment of atopic dermatitis. Expert Rev Clin Immunol. 2020;16:955-962. doi:10.1080/1744666X.2021.1828068

18. Bao L, Zhang H, Chan LS. The involvement of the JAK-STAT signaling pathway in chronic inflammatory skin disease atopic dermatitis. JAKSTAT. 2013;2:e24137. doi:10.4161/jkst.24137

19. Napolitano M, Marasca C, Fabbrocini G, Patruno C. Adult atopic dermatitis: new and emerging therapies. Expert Rev Clin Pharmacol. 2018;11:867-878. doi:10.1080/17512433.2018.1507734

20. Rodrigues MA, Torres T. JAK/STAT inhibitors for the treatment of atopic dermatitis. J Dermatolog Treat. 2020;31:33-40. doi:10.1080/ 09546634.2019.1577549

21. Napolitano M, Fabbrocini G, Cinelli E, Stingeni L, Patruno C. Profile of baricitinib and its potential in the treatment of moderate to severe atopic dermatitis: a short review on the emerging clinical evidence. J Asthma Allergy. 2020;13:89-94. doi:10.2147/JAA.S206387

22. New oral treatment for moderate to severe atopic dermatitis. Available from: https://www.ema.europa.eu/en/news/new-oral-treatmentmoderate-severe-atopic-dermatitis. Accessed January 18, 2021.

23. Gooderham MJ, Forman SB, Bissonnette R, et al. Efficacy and safety of oral janus kinase 1 inhibitor abrocitinib for patients with atopic dermatitis: a phase 2 randomized clinical trial. JAMA Dermatol. 2019;155:1371-1379. doi:10.1001/jamadermatol.2019.2855

24. Peeva E, Hodge MR, Kieras E, et al. Evaluation of a Janus kinase 1 inhibitor, PF-04965842, in healthy subjects: a Phase 1, randomized, placebo-controlled, dose-escalation study. $\mathrm{Br} J$ Clin Pharmacol. 2018;84:1776-1788. doi:10.1111/bcp.13612

25. Simpson EL, Sinclair R, Forman S, et al. Efficacy and safety of abrocitinib in adults and adolescents with moderate-to-severe atopic dermatitis (JADE MONO-1): a multicentre, double-blind, randomised, placebo-controlled, Phase 3 trial. Lancet. 2020;396:255-266. doi:10.1016/S0140-6736(20)30732-7

26. Silverberg JI, Simpson EL, Thyssen JP, et al. Efficacy and safety of abrocitinib in patients with moderate-to-severe atopic dermatitis: a randomized clinical trial. JAMA Dermatol. 2020;156:863-873. doi:10.1001/jamadermatol.2020.1406 
27. Study evaluating efficacy and safety of PF-04965842 and dupilumab in adult subjects with moderate to severe atopic dermatitis on background topical therapy (JADE compare). Available from: https:// www.clinicaltrials.gov/ct2/show/NCT03720470?term= NCT03720470\&draw=2\&rank=1. Accessed January 18, 2021.

28. Study to investigate efficacy and safety of PF-04965842 in subjects aged 12 years and over with moderate to severe atopic dermatitis with the option of rescue treatment in flaring subjects. Available from: https:/www.clinicaltrials.gov/ct2/show/NCT03627767?term= abrocitinib\&cond $=$ Atopic + Dermatitis $\&$ draw $=2 \&$ rank $=5$. Accessed January 18, 2021.

29. Study to evaluate efficacy and safety of PF-04965842 with or without topical medications in subjects aged 12 years and older with moderate to severe atopic dermatitis (JADE EXTEND). Available from: https:/www.clinicaltrials.gov/ct2/show/NCT03422822?term=abrociti nib\&cond $=$ Atopic + Dermatitis $\&$ draw $=2 \&$ rank $=3$. Accessed January $18,2021$.
30. Study of abrocitinib compared with dupilumab in adults with moderate to severe atopic dermatitis on background topical therapy. Available from: https://www.clinicaltrials.gov/ct2/show/ NCT04345367?term $=$ abrocitinib\&cond $=$ Atopic + Dermatitis\&draw $=$ 2\&rank=2. Accessed January 18, 2021.

31. Abrocitinib expanded access protocol in adolescents and adults with moderate to severe atopic dermatitis. Available from: https://www. clinicaltrials.gov/ct2/show/NCT04564755?term=abrocitinib\&cond= Atopic+Dermatitis\&draw=2\&rank=1. Accessed January 18, 2021.

32. Study evaluating the mechanism of action of PF-04965842 monotherapy for moderate-to-severe atopic dermatitis (JADE MOA). Available from: https://www.clinicaltrials.gov/ct2/show/ NCT03915496? term $=$ abrocitinib\&cond $=$ Atopic + Dermatitis \&draw $=$ 2\&rank=4. Accessed January 18, 2021.

\section{Publish your work in this journal}

Drug Design, Development and Therapy is an international, peerreviewed open-access journal that spans the spectrum of drug design and development through to clinical applications. Clinical outcomes, patient safety, and programs for the development and effective, safe, and sustained use of medicines are a feature of the journal, which has also been accepted for indexing on PubMed Central. The manuscript management system is completely online and includes a very quick and fair peer-review system, which is all easy to use. Visit http://www. dovepress.com/testimonials.php to read real quotes from published authors. 